\title{
JESÚS JIMÉNEZ ORTONEDA, INTERVENTOR MILITAR EN EL RIF (1911-1936) ${ }^{1}$
}

\author{
José LUIS VilLANOVA \\ Universidad de Girona \\ LUIS URTEAGA \\ Universidad de Barcelona
}

RESUMEN: Este artículo analiza, a partir de documentación original, y en gran parte inédita, la trayectoria profesional de Jesús Jiménez Ortoneda, quien desarrolló la práctica totalidad de su carrera militar en Marruecos, entre 1907 y 1936. Jiménez Ortoneda ocupó importantes puestos en la Administración del Protectorado español (interventor de cabila, jefe de la sección política y del servicio de información de la Oficina Central de Intervenciones de Melilla y subdelegado de Asuntos Indígenas), dominó con cierta fluidez el árabe y el chelja, y alcanzó un notable conocimiento del territorio del Rif. Por otra parte, su carrera militar —en la que alcanzó el grado de teniente coronel — se caracterizó por la más estricta profesionalidad y fue uno de los pocos militares africanistas que sirvieron fielmente a la República y que no se sumaron a la sublevación militar de 1936. El estudio de su trayectoria permite contrastar algunas de las ideas establecidas acerca de la formación y desempeño de los interventores en el Protectorado.

Palabras Clave: Protectorado español de Marruecos. Policía Indígena. Interventores. Política colonial. Comisión de Límites de Marruecos. Ejército colonial.

José Luis Villanova es profesor en la Universidad de Girona. Dirección para correspondencia: Departamento de Geografía, Historia e Historia del Arte, Facultad de Letras, Universidad de Girona, Pl. Ferrater Mora 1, 17071, Girona.E-mail: josel.villanova@udg.edu

Luis Urteaga es profesor en la Universidad de Barcelona. Dirección para correspondencia: Departamento de Geografía Humana, Facultad de Geografía e Historia, Universidad de Barcelona, C/ Montalegre 6,08001,Barcelona.E-mail: urteaga@ub.edu

1 Este trabajo se ha realizado en el marco del proyecto de investigación 2007 EBRE 2, financiado por la Agència de Gestió d'Ajuts Universitaris i de Recerca de la Generalitat de Catalunya. Queremos agradecer a Mercedes López Vienne, Mercedes Jiménez López y Guillermo Jiménez López las facilidades que nos han concedido para la consulta de su archivo familiar. 


\section{A MILITARY OFFICER IN RIF: JESÚS JIMÉNEZ ORTONEDA (1911-1936)}

ABSTRACT: This paper uses original and for the most part unpublished documentation in order to examine the career of Jesús Jiménez Ortoneda, a highly successful career officer who served in the Spanish Protectorate of Morocco between 1907 and 1936. He occupied important positions in the political administration of the Protectorate (as director of the political section of Melilla's Oficina Central de Intervenciones and a senior official in the Department of Indigenous Affairs); he was fluent in Arab and Tamazight, and gained a sound knowledge of the geography of the Rif mountains. His military career, in which he achieved the rank of lieutenant colonel, was characterized by his strictly professional attitude. He was one of the few career officers in Africa who were faithful to Spain's republican government and who did not participate in the military uprising of 1936. This discussion of his career brings into question some well-established ideas concerning Spanish colonial policy in Morocco.

KEY WORDS: Spanish Protectorate of Morocco. Indigenous Police. Colonial Officers. Colonial Policy. Morocco's Border Commission. Colonial Army.

Los interventores fueron la pieza clave de la política colonial española en el Protectorado de Marruecos (1912-1956). Organizados en 1923, su principal función consistía en fiscalizar y orientar la actuación de las autoridades marroquíes de las ciudades y de las setenta cabilas en las que se agrupaba la población de la zona. El sistema de las Intervenciones y el papel que desempeñaron los interventores en el Protectorado han sido analizados en los últimos años desde diversas disciplinas, señaladamente la antropología, la historia y la geografía ${ }^{2}$. Pero la mayor parte de estos trabajos, con excepción de los dedicados a

2 Véanse, por ejemplo, TORRes Escobar, Francisco, «La intervención en el Protectorado de Marruecos (1936-1956)», Revista de la Universidad Complutense, XXVIII (116) (1980), págs. 465486; Driessen, Henk, On the Spanish-Moroccan Frontier. A Study in Ritual, Power and Ethnicity, Oxford, Berg, 1992; MOGA Romero, Vicente, «Etnografía e intervención militar en el Rif durante el protectorado español de Marruecos», Fundamentos de Antropología, 4-5 (1996), págs. 253-255; MATEO Dieste, Josep Lluís, «La oficina de intervención como espacio de interacción socio-política entre el muraquib y la cabila: de la ideología colonial a las prácticas cotidianas», en: RODRíGUEZ Mediano, Fernando y Felipe, Helena de (eds.), El Protectorado español en Marruecos. Gestión colonial e identidades, Madrid, CSIC, 2002, págs. 139-180; «La paraetnografía militar colonial: poder y sistemas de clasificación social», en: LÓPEZ GARcíA, Bernabé, RAMíreZ, Ángeles (eds.), Antropología y antropólogos en Marruecos. Homenaje a David Montgomery Hart, Barcelona, Bellaterra, 2002, págs. 113-133; La "hermandad» hispano-marroquí. Política y religión bajo el Protectorado español en Marruecos, Barcelona, Bellaterra, 2003; y «El interventor y el caíd. La política colonial española frente a la justicia marroquí durante el Protectorado de Marruecos (1912-1956)», Hispania, LXVII (226) (2007), págs. 643-677; Villanova, José Luis, «La formación de los interventores en el Protectorado español en Marruecos (1912-1956)», en: RodRíGUEZ MEDiAnO, Fernando y FELIPE, Helena de (eds.), El Protectorado..., págs. 247-280; «La pugna entre militares y civiles por el control de la actividad interventora en el Protectorado español en Marruecos (1912-1956)», Hispania, LXV (220) (2005), págs. 683-716; «Los interventores del Protectorado español en Marruecos (1912- 
la figura de Emilio Blanco Izaga ${ }^{3}$, han abordado el tema desde una perspectiva de conjunto, y faltan aportaciones precisas de carácter biográfico que permitan trazar un perfil más ajustado de los interventores y, por extensión, de la administración colonial.

Pese a esta carencia historiográfica, la imagen difundida de los interventores es manifiestamente negativa. Diversos trabajos han destacado como rasgos característicos de este colectivo su dejadez e incompetencia, los abusos o el desprecio que manifestaban hacia la población marroquí, y su desconocimiento de la sociedad local. No obstante, es bien cierto que algunos interventores no acaban de encajar en esta imagen, como es el caso, por ejemplo, del citado Blanco Izaga y, como trataremos de demostrar, del teniente coronel Jesús Jiménez Ortoneda ${ }^{4}$.

La figura de Jiménez Ortoneda nos parece interesante por diversas razones. Fue un militar que pasó la práctica totalidad de su carrera en Marruecos, ocupando los puestos de interventor de cabila, responsable de la sección política de la Oficina Central de Intervenciones de Melilla y subdelegado de Asuntos Indígenas en Tetuán. Su estancia en el Rif le permitió adquirir un buen conocimiento de amplias zonas de este territorio, por lo que fue nombrado agregado a la Comisión Internacional de Límites de Marruecos. También fue un profesional del Ejército de África que sirvió lealmente a la República y que, al no tomar parte en la sublevación de 1936, pagó su fidelidad con la cárcel. De ideas africanistas, y profundamente católico, su carrera quedó truncada cuando los militares insurrectos tomaron el poder.

El desenlace de la Guerra Civil condujo al ostracismo, y a menudo a la muerte, a la cárcel o al exilio, a los militares profesionales que sirvieron leal-

1956) como agentes geopolíticos», Ería, 66 (2005), págs. 93-111; y Los interventores. La piedra angular del Protectorado español en Marruecos, Barcelona, Bellaterra, 2006.

3 Véanse HART, David M., «Introducción 1. Emilio Blanco Izaga y el Protectorado español en Marruecos», en: Moga Romero, Vicente, Bravo Nieto, Antonio (eds.), Emilio Blanco Izaga. Coronel en el Rif. Una selección de su obra, publicada e inédita, sobre la estructura sociopolítica de los rifeños del Norte de Marruecos, Melilla, Ayuntamiento de Melilla \& UNED-Centro Asociado de Melilla, 1995, págs. 25-62; Bravo Nieto, Antonio, Moga Romero, Vicente, "Contribution espagnole à la connaissance de la société coloniale marocaine: Emilio Blanco Izaga (1892-1949)», Revue Maroc/Europe, 8 (1995), págs. 247258; Moga Romero, Vicente, «La celebración del misterio rifeño. Emilio Blanco de Izaga en Beni Aammart», en: BLANCO IZAGA, Emilio, La vivienda rifeña. Ensayo de característica e interpretación con ilustraciones del autor (1930), Ceuta \& Melilla, Ciudades Autónomas de Ceuta y Melilla, Consejerías de Cultura, 2000, págs. 17-102; y El Rif de Emilio Blanco Izaga. Trayectoria militar, arquitectónica y etnográfica en el Protectorado de España en Marruecos, Barcelona, Bellaterra, 2009.

4 Algunos interventores que elaboraron estudios etnográficos de campo de cierta calidad se citan en: HART, David M., «Spanish Colonial Ethnography in the Rural and Tribal Northern Zone of Morocco, 1912-1956: An Overview and an Appraisal», The Journal of North African Studies, IV (2) (1999), págs. 110-130; Benjelloun, Abdelmajid, «L’identité jeblie et la sociologie coloniale espagnole», en: ZougGari, Ahmed, Vignet-ZunZ, Jawjar, MessaOudi, Leïla (coords.), Les Jbala. Espace et Pratiques, Kenitra, Université Ibn Tafaïl, 2001, págs. 191-206; LóPEZ BARGADOs, Alberto y MATEO Dieste, Josep Lluís, «Parler au désert. Bilan de l'anthropologie du Magreb en Espagne», Prologues. Revue maghrébine du livre, 32 (2005), págs. 110-125. 
mente a la República. La historiografía militar franquista sepultó en el olvido su memoria. Paradójicamente, la nueva historia militar no ha hecho mucho por rehabilitarles. En particular, los militares pertenecientes al Ejército de África han debido cargar colectivamente con el baldón de golpistas. La trayectoria de Jesús Jiménez Ortoneda, que hemos podido reconstruir a partir del manejo de fuentes primarias, se aleja de los tópicos.

Este trabajo consta de cuatro partes. La primera da cuenta del arranque de la carrera militar de Jiménez Ortoneda, destacando su larga permanencia en las tropas de la Policía Indígena. La segunda analiza su actividad como interventor y responsable del servicio de información de la Oficina Central de Intervenciones de Melilla. En la tercera se describe su participación como experto en la Comisión Internacional de Límites de Marruecos. La cuarta y última considera su labor como subdelegado de Asuntos Indígenas, y el abrupto y amargo final de su carrera profesional.

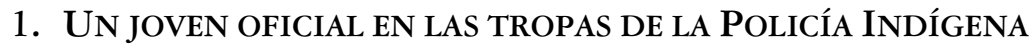

Jesús Jiménez Ortoneda, hijo del capitán de Infantería Juan Jiménez Conde y de Concepción Ortoneda Alabart, nació en A Coruña el 18 de abril de 1887. Siguiendo la trayectoria profesional de su padre, y de su hermano Juan, a los diecisiete 17 años ingresó en la Academia de Infantería de Toledo (6-9-1904), donde se licenció como $2 .^{\circ}$ teniente de Infantería en 1907. Su primer destino, siguiendo los pasos de su hermano , fue el Regimiento de Infantería de África $\mathrm{n}^{\mathrm{O}} 68$ con sede en Melilla, al que se incorporó en agosto de aquel año. Desde aquel momento prácticamente no abandonaría Marruecos hasta que finalizó su carrera profesional en 1939, tras pasar tres años detenido y haber sido separado del servicio ${ }^{6}$.

El joven oficial de origen gallego llegó a Melilla, con veinte años, en un momento crucial para la historia de la acción colonial española en Marruecos. En 1903 El Rogui — pretendiente al trono jerifiano- había ocupado la alcazaba de Farhana e impuesto su dominio sobre el Rif oriental 7 después de derrotar a las tropas del Sultán y conseguir la adhesión de las cabilas de la región.

5 Juan Jiménez Ortoneda, capitán de Infantería del batallón de Cazadores de Ciudad Rodrigo, fue herido en combate el 12 de septiembre de 1911, en las proximidades del río Kert, y falleció el día siguiente. Por su heroico comportamiento le fue concedida la Cruz Laureada de 2. ${ }^{\text {a }}$ clase.

6 Archivo General Militar de Segovia - AGMS, en adelante-, Leg. J-53.

7 En sentido geográfico estricto, el término 'Rif corresponde a la región del litoral mediterráneo marroquí y su traspaís inmediato comprendidos entre el río Mestasa y la península del cabo de Tres Forcas. Una síntesis geográfica de la Zona del Protectorado, en general, y del Rif, en particular, se encuentra en NoguÉ, Joan, VillanOVA, José Luis, «La zona norte del protectorado español en Marruecos. El marco geográfico», en: NoGUÉ, Joan, VillanOVA, José Luis (eds.), España en Marruecos (1912-1956). Discursos geográficos e intervención territorial, Lleida, Milenio, 1999, págs. 102-141. 
Sin embargo, su decisión de otorgar concesiones mineras a compañías francesas y españolas, y su despótico gobierno, motivaron que diversas tribus se levantaran contra él ${ }^{8}$. La confusa situación fue aprovechada por el general José Marina Vega, gobernador militar de Melilla, para ampliar la presencia española en la zona: tropas españolas ocuparon la Restinga en febrero de 1908 y Cabo de Agua al mes siguiente. La ocupación fue justificada con la excusa de ejercer la misión de policía que había establecido el Acta de Algeciras de 19069. Pero, en el primer caso se trataba de evitar la instalación de una factoría francesa, como la que había existido entre 1903 y 1906 y que había sido una cobertura para proporcionar armas a El Rogui; mientras que con la ocupación de Cabo de Agua se deseaba restar apoyos al pretendiente en la cabila de Quebdana y proporcionar una base de aprovisionamiento para la guarnición de las islas Chafarinas ${ }^{10}$.

Tras la ocupación de Cabo de Agua, Jiménez Ortoneda fue destinado en diversas ocasiones a la zona de Quebdana, donde participó en avanzadas y operaciones de reconocimiento por la rábida de Beni-Riaten, el vado Ragay y las inmediaciones del río Muluya ${ }^{11}$. Este tipo de acciones, que volvería a repetir en distintos escenarios, le proporcionarían un notable conocimiento de diversas regiones del Rif.

La derrota de El Rogui a manos de los rifeños y su huida a finales de 1908 crearon un vacío de poder en la región que fue aprovechado por Mohammed Ameizan para agrupar bajo su jefatura a las cabilas apelando a la resistencia armada contra la presencia española. El ataque de los rifeños el 9 de julio de 1909 a las obras del ferrocarril minero que se estaba construyendo supuso el inicio de la llamada "guerra de 1909», en la que las tropas españolas sufrirían el desastre del Barranco del Lobo. Después de varios meses de enfrenamientos, las autoridades de Melilla obtuvieron la sumisión de notables de diversas fracciones y cabilas del Rif oriental sobre las que extendieron su control tomando como excusa los acuerdos adoptados en el Acta de Algeciras y dieron por finalizado el conflicto a finales del mes de noviembre ${ }^{12}$.

8 Sobre los intereses franco-españoles en las minas del Rif, véanse MORALES LEZCANO, Víctor, El colonialismo bispano-francés en Marruecos (1898-1927), Madrid, Siglo XXI, 1976, págs. 69-87; Madariaga, María Rosa de, España y el Rif. Crónica de una historia casi olvidada, Melilla, Ciudad Autónoma de Melilla \& UNED-Centro Asociado de Melilla, 1999, págs. 109-199; AzIZA, Mimoun, La sociedad rifeña frente al Protectorado español de Marruecos (1912-1956), Barcelona, Bellaterra, 2003, págs. 98-107; RuIZ ALbÉNIZ, Víctor, España en el Rif (1908-1921), Melilla, Ciudad Autónoma de Melilla, 2007 [1921], págs. 43-47.

9 Lobera Girela, Cándido, El Problema Rifeño, Melilla, El Telegrama del Rif, 1909.

10 Balfour, Sebastián, Abrazo mortal. De la guerra colonial a la Guerra Civil en España y Marruecos (1909-1939), Barcelona, Península, 2002.

11 AGMS, Leg. J-53.

12 Sobre la «guerra de 1909» y la posterior «campaña del Kert» (1911-1912) véanse AYACHE, G., Les origines de la guerre du Rif, Paris \& Rabat, Société Marocaine des Éditeurs Réunis \& Publicactions de la Sorbonne, 1981, págs. 119-152; MADARIAGA, María Rosa de, España y ..., págs. 277-304 y 326-339 y En el Barranco del Lobo. Las guerras de Marruecos, Madrid, Alianza, 2005, págs. 
Jiménez Ortoneda, que había ascendido al grado de primer teniente por antigüedad (13-7-1909), participó en numerosos combates, entre ellos en el sostenido en el Barranco del Lobo el 23 de julio. Por su comportamiento, en éste y en otros enfrentamientos, se le concedió la Cruz de $10^{\mathrm{a}}$ clase del Mérito Militar $^{13}$. El 26 de julio de 1911 fue destinado a la Policía Indígena y se incorporó a la 3. ${ }^{a}$ Mía (Compañía) en el Zoco el Had de Beni Sicar. A partir de aquel momento, y con excepción de breves periodos, ya no abandonaría su vinculación con «asuntos indígenas» hasta la finalización de su carrera profesional. Este destino le permitiría mantener un contacto directo con los rifeños durante más de dos décadas.

La Policía Indígena había sido creada por un Real Decreto de 31 de diciembre de 1909. La ampliación del territorio marroquí bajo influencia española, a consecuencia de la guerra de 1909, motivó que el Gobierno se planteara la conveniencia de organizar las primeras tropas coloniales españolas en Marruecos. Este tipo de fuerzas había proporcionado a Francia excelentes resultados en Argelia y, con su creación, las autoridades españolas esperaban obtener beneficios tanto en la Península como en Marruecos. En el primer caso, se trataba de evitar la repetición de sucesos como los de la Semana Trágica de 1909. En el segundo, el atractivo de la paga podía mermar los contingentes de los resistentes. Tras diversos estudios, y tomando como referencia directa los bureaux arabes creados por el mariscal Bugeaud en Argelia ${ }^{14}$, se organizaron las tropas de Policía Indígena de Melilla, bajo el mando de oficiales del Ejército español y a las órdenes del general jefe de Estado Mayor. Sus atribuciones, vagamente concretadas en la disposición oficial, consistían en «atender a la conservación del orden, a los servicios de policía militar y demás que se les encomienden» en Melilla y los territorios ocupados de Guelaya.

La posterior expansión española sobre el territorio marroquí obligó al gobierno a perfeccionar los organismos encargados de afianzar su presencia en las zonas ocupadas. El Real Decreto de 5-1-1912 creó la Subinspección de Tropas y Asuntos Indígenas que se organizó en una oficina central y oficinas destacadas en las cabilas. Un coronel de Estado Mayor ocupaba la jefatura de las fuerzas de la Policía y se encontraba al frente de la Oficina Central de Melilla, mientras que capitanes y tenientes estaban al mando de las destacadas. Estas últimas debían velar por el mantenimiento de «la tranquilidad y el orden» y obtener todo tipo de datos que pudieran interesar al mando para marcar la política a seguir. Evidentemente, el decreto citado no otorgaba a los oficiales españoles atribuciones interventoras cerca de las autoridades marroquíes - $\mathrm{a}$ las cuales no tenían todavía derecho por los tratados firmados hasta el momen-

\footnotetext{
51-58 y 73-79; Balfour, Sebastián, Abrazo mortal..., págs. 50-63; Villalobos, Federico, El sueño colonial. Las guerras de España en Marruecos, Barcelona, Ariel, 2004, págs. 155-189.

13 AGMS, Leg. J-53.

14 Sobre los bureaux arabes véase FrÉMAUX, Jacques, Les bureaux arabes dans l'Algérie de la conquête, Paris, Éditions Denoël, 1993.
} 
to- - pero apuntaba que ejercerían «la autoridad gubernativa» en los poblados bajo su control como delegados del capitán general de Melilla ${ }^{15}$.

Tras la guerra de 1909, no todas las fracciones y cabilas del Rif oriental se habían sometido a las autoridades españolas, por lo que la efervescencia continuaba en la región. Después de unos meses de aparente calma, que fueron aprovechados por las tropas españolas para aproximarse al río Kert, el 24 de agosto de 1911 los rifeños atacaron a una misión topográfica que trabajaba en las proximidades de Isfahen. Este ataque y la posterior reacción española son considerados el punto de partida de la llamada «campaña del Kert», que se prolongó diez meses. El fallecimiento de Amezian en combate, en mayo de 1912, supuso el final de la resistencia organizada y la desmovilización de la mayor parte de los rifeños. Con estas operaciones, España había conseguido ampliar su zona de influencia desde Melilla hasta el cauce del Kert. Y aunque las escaramuzas continuarían produciéndose irregularmente, esta frontera permanecería inalterable durante varios años. Durante la campaña, Jiménez Ortoneda participó en diversos combates, fue condecorado con dos Cruces de $1 .^{a}$ Clase de María Cristina, y desde el 24 de septiembre de 1911 quedó a las órdenes del general Salvador Díaz Ordóñez como encargado del servicio de información ${ }^{16}$. Probablemente, el nombramiento refleja el interés y el conocimiento que Jiménez Ortoneda empezaba a tener en el Rif oriental.

El 2 de marzo de 1912, Jiménez Ortoneda se hizo cargo de la oficina de Asuntos Indígenas del Zoco el Had de Beni Sicar, iniciando su actividad en el control de las cabilas. En aquella oficina, además de continuar efectuando nuevos reconocimientos y operaciones en vanguardia — cuando le era requeridorealizó el padrón en diversos poblados, contribuyó a formar una harka auxiliar, e inició formalmente sus estudios sobre el territorio del Rif. Su primera publicación sobre el tema, realizada en colaboración con el capitán Emilio Villegas y el teniente Ricardo Satallé, lleva por título Memoria geográfica, histórica y estadística de la kabila de Beni-Sicar, y fue editada por los Talleres del Depósito de la Guerra en 1913.

El 20 de febrero de 1914 fue ascendido a capitán y, pocos días más tarde, contrajo matrimonio en Melilla con María del Amparo Albéniz Alonso (Figura $\mathrm{n}^{\mathrm{o}}$ 1). El matrimonio tuvo cuatro hijos: Jesús, Fernando, Julio y María del Amparo. Tal como era habitual, el ascenso provocó su traslado y, de marzo a mayo

15 Tres años más tarde, la Real Orden Circular de 31-7-1914 reorganizó las Fuerzas Indígenas e insistió en que la Policía tenía la misión principal de "garantizar el orden y contribuir a la política que se indique por la autoridad superior», aunque no se excluía su participación en operaciones militares. La Real Orden también dispuso que de cada oficina central de la Policía —el Real Decreto de 15-3-1913 y la Real Orden Circular de 25-4-1913 habían organizado oficinas centrales en Larache y Ceuta — dependieran oficinas principales y destacadas, o de información. En las primeras se organizarían mías, bajo el mando del capitán responsable de la oficina. ViLlanova, José Luis, Los interventores..., págs. 28-37.

16 AGMS, Leg. J-53. 
de 1916, fue destinado a diversos regimientos de Infantería, con los que participó en algunas pequeñas acciones para afianzar la influencia española en la cabila de Beni Bu Yahi. Por su actuación en este periodo le fue concedida la Cruz de $1 .{ }^{a}$ Clase del Mérito Militar con distintivo rojo ${ }^{17}$.

Figura N ${ }^{0}$ 1: Jesús JimÉNEZ ORTONEDA y MARÍA DEL AMPARo JimÉNEZ AlONSO

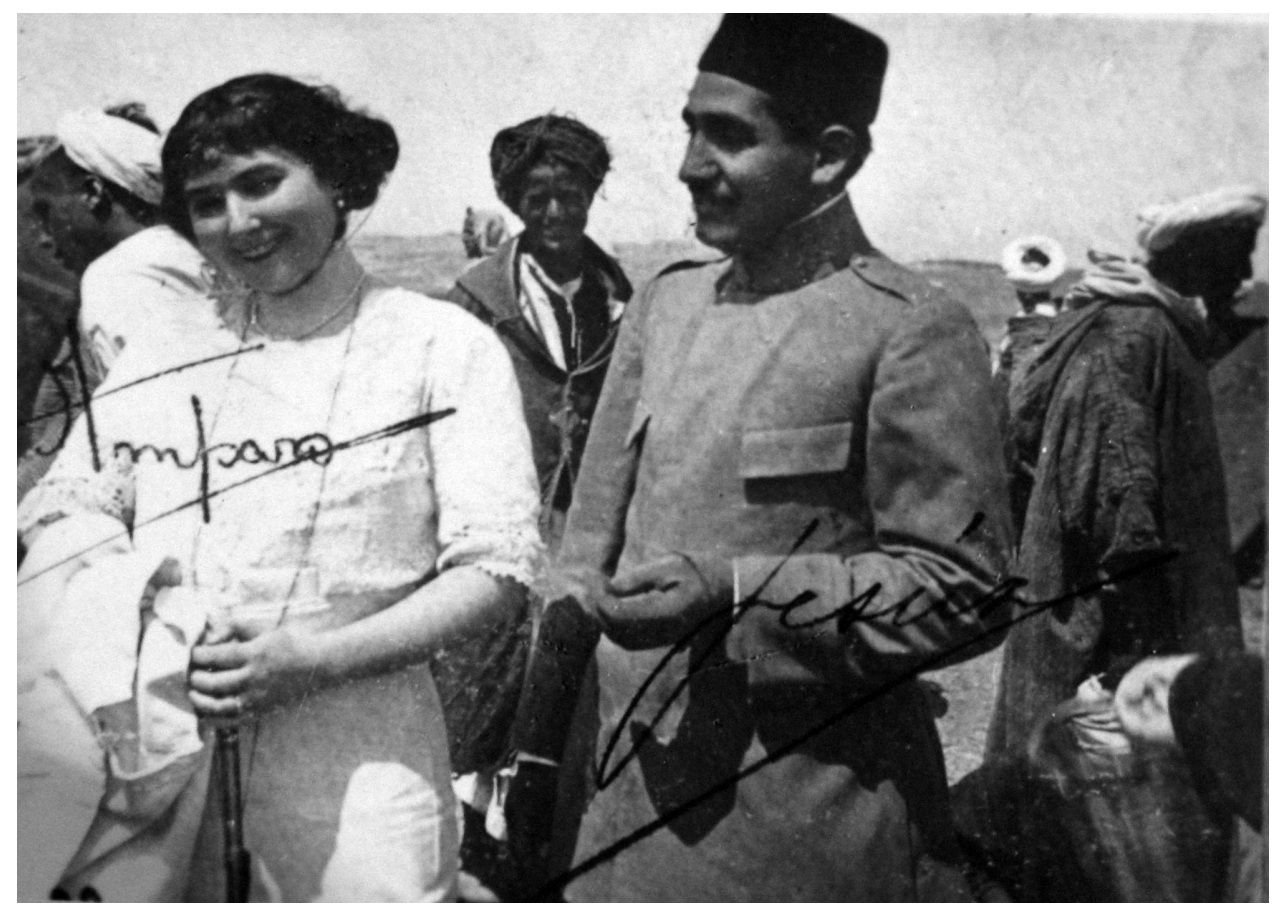

Archivo familiar de Jiménez Ortoneda.

La decisión del general Luis Aizpuru y Mondéjar, comandante general de Melilla, de establecer algunas nuevas posiciones en la orilla izquierda del Kert para extender la influencia española hacia el Rif central, debió motivar la creación de nuevas mías de Policía Indígena, para las que era necesario contar con oficiales preparados. Posiblemente, por esta razón, el 30 de junio de $1916 \mathrm{Ji}$ ménez Ortoneda fue destinado al mando de la 10. ${ }^{a}$ Mía, con la que participó en las pequeñas operaciones — denominadas «rectificaciones de línea»- que se llevaron a cabo en las cabilas de Beni Said, Metalza y Beni Bu Yahi. El 1 de

17 AGMS, Leg. J-53 y «Expediente de la Pensión de Retiro de Jesús Jiménez Ortoneda», no 2912/08. Ministerio de Defensa. Subdirección General de Personal Militar. Área de Pensiones. 
enero de 1918 fue nombrado jefe de la Oficina de Información de Iarf el Baax (Beni Said), hasta que le fue confiado el mando de la 2. ${ }^{a}$ Mía con sede en Nador el 8 de julio del mismo año ${ }^{18}$. En su nuevo destino, realizó tareas de información en Cabo de Agua e inició la confección de estadísticas en la cabila de Mazuza. De esa época datan las primeras referencias que tenemos de su esfuerzo para dominar el chelja, la lengua hablada por la mayor parte de las cabilas del Rif oriental: en julio de 1919 obtuvo la calificación de «muy bueno» en los exámenes del $2 .^{\circ}$ curso de chelja de la Academia Oficial de Árabe de Melilla.

El 17 de abril de 1921, Jiménez Ortoneda se hizo cargo de la Oficina de Información de Afsó (Beni Bu Yahi), donde volvió a dar muestras de su conocimiento de la sociedad rifeña y de su habilidad de trato con la población autóctona al arreglar una «deuda de sangre» entre dos familias. Aquel mismo mes fue agregado eventualmente a la Comisión Internacional de Límites ${ }^{19}$, aspecto del que nos ocuparemos en un próximo apartado. Su conocimiento sobre esta cabila fronteriza con la Zona francesa fue determinante para este nombramiento.

Durante el mes de junio, y en el marco de las operaciones que desarrollaba el general Manuel Fernández Silvestre para penetrar hacia el centro del Rif, formó parte de las fuerzas de sostén a la columna que conquistó Abarrán, cooperó en la ocupación de Igueriben, y participó en servicios de seguridad para impedir el corte de las comunicaciones con Annual. El 22 de julio, a raíz de la desorganizada evacuación de Annual, el caos más absoluto se apoderó de la zona. Jiménez Ortoneda se vio envuelto en aquellos dramáticos acontecimientos en los que el Estado Mayor desapareció, la cadena de mando se desmoronó rápidamente y la inmensa mayoría de los oficiales y de la tropa trataron de huir despavoridos. No sabemos a ciencia cierta cuál fue su comportamiento aquel funesto día, pero logró salir con vida y el 23 había llegado a Nador y el 24 a Melilla ${ }^{20}$. Al día siguiente, «como conocedor del terreno», quedó a las inmediatas órdenes del general José Sanjurjo, agregado temporalmente al Cuartel General ${ }^{21}$.

La contraofensiva española se inició en septiembre de 1921 y en enero las tropas españolas llegaron de nuevo al Kert, donde se consolidó el frente a lo

18 AGMS, Leg. J-53. Las oficinas de información estaban encargadas de proporcionar información del estado político en la cabila a la correspondiente oficina principal y desarrollar la política de atracción hacia las zonas no dominadas. Villanova, José Luis, Los interventores..., págs. 178-189.

19 AGMS, Leg. J-53.

20 En el expediente de su primera propuesta de ascenso a comandante por méritos de guerra, resuelto negativamente en marzo de 1924, el fiscal señaló que el procedimiento para averiguar su conducta durante los sucesos del 22 de julio se había sobreseído «provisionalmente», aunque la instrucción sumarial se había suspendido definitivamente en lo que concernía a su regreso a Melilla desde Nador. Véase «Expediente de la Pensión de Retiro de Jesús Jiménez Ortoneda». Su declaración en el «Expediente Picasso» se encuentra en Expediente Picasso, México, Frente de Afirmación Hispanista, 1976, primera edición facsimilar [1922], págs. 467-471.

21 AGMS, Leg. J-53. 
largo de varios meses ${ }^{22}$. En estas operaciones, Jiménez Ortoneda, que seguía como agregado al Cuartel General de Sanjurjo, cooperó en la ocupación de varias posiciones, asistió a convoyes y mantuvo contactos con jefes de cabila adictos para conseguir el rescate de varios prisioneros (Figura $\mathrm{n}^{\circ} 2$ ). El 18 de noviembre de 1921 fue herido por arma de fuego en la ocupación de los Montes Uixan y tuvo que permanecer de baja más de dos meses. Por estas actuaciones fue citado como distinguido por el general Sanjurjo, quien destacó sus valiosos conocimientos del terreno, y recibió la Medalla del Sufrimiento por la Patria ${ }^{23}$.

\section{Figura N ${ }^{\mathrm{O}}$ 2: EL CAPITÁN DE LA POLICÍA INDÍGENA Jesús JimÉnEZ OR- TONEDA (A LA DERECHA) EN LA CABILA DE METALZA (1922)}

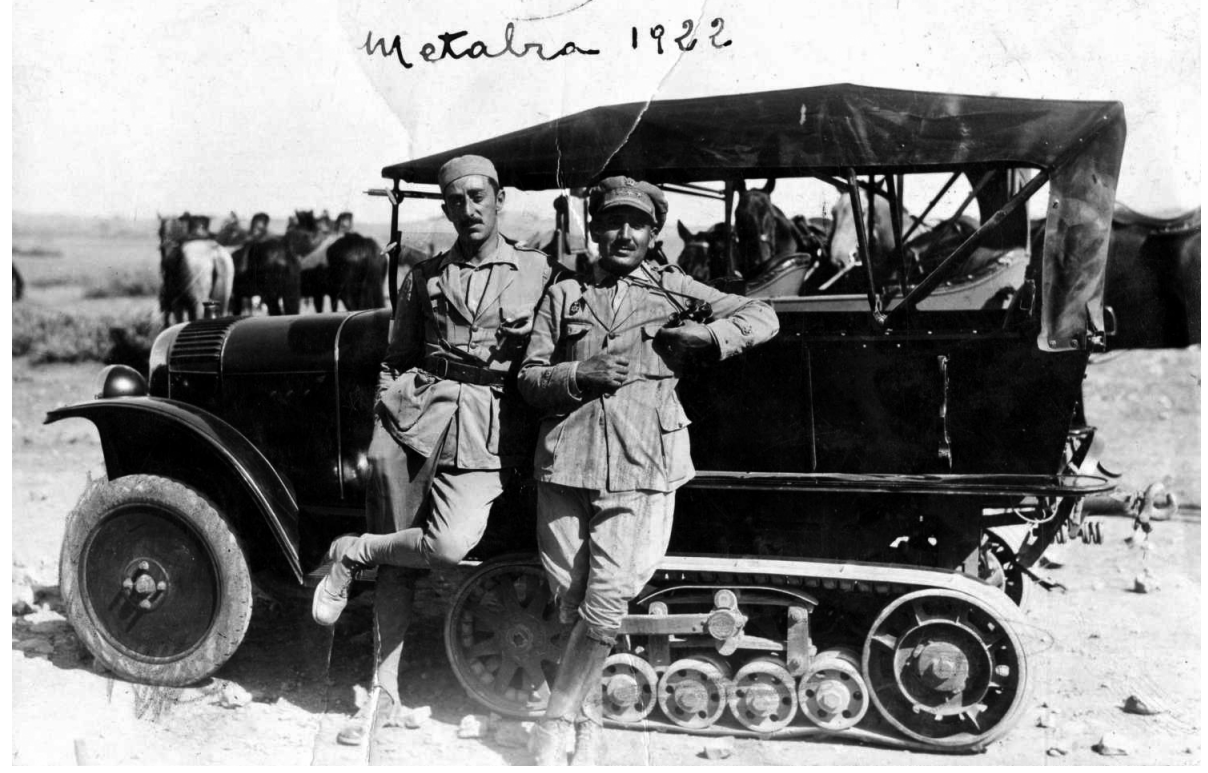

Archivo familiar de Jiménez Ortoneda.

22 Sobre la Guerra del Rif véanse WoOlman, David S., Abd el-Krim y la guerra del Rif, Vilassar de Mar, Oikos-Tau, 1971 [1968]; Abd el Krim et la République du Rif. Actes du coloque international d'études historiques et sociologiques, 18-20 janvier 1973, Paris, Librairie François Maspéro, 1976; AYACHE, Germain, Les origines... y La guerre du Rif, Paris, L'Harmattan, 1996; DaOUD, Zakya, Abdelkrim. Une épopée d'or et de sang, Paris, Séguier, 1999; MAdARiaga, María Rosa de, España y..., págs. 385-494 y En el Barranco..., págs. 118-397; PENNELL, C.R., La guerra del Rif. Abdelkrim elJattabi y su Estado rifeño, Melilla, Ciudades Autónomas de Ceuta y Melilla \& UNED-Centro Asociado de Melilla, 2001 [1986]; BALFOUR, Sebastián, Abrazo mortal...; Villalobos, Federico, El sueño..., p. 191-276.

23 AGMS, Leg. J-53. 
Una vez alcanzada la línea del Kert se hizo necesario intensificar la labor política en retaguardia. En enero de 1923, Jiménez Ortoneda se hizo cargo de la oficina de Batel, regresando a la cabila de Beni Bu Yahi. Allí organizó la recluta de la $7 .{ }^{a}$ Mía de Policía y participó en diversas operaciones militares. Los jefes de las oficinas de Policía Indígena, una vez ocupada una nueva posición, debían asegurar el control del territorio y de la población, iniciar el estudio del terreno limítrofe insumiso, con la intención de reunir información sobre todos aquellos aspectos (topográficos, políticos, económicos) susceptibles de ser utilizados por el mando para dominar la resistencia, y atraerse a los marroquíes ${ }^{24}$. En este sentido, mantuvo entrevistas políticas con los jefes de la cabila, intervino en el rescate de prisioneros, reorganizó los zocos y efectuó la recogida de armamento de los rifeños que se iban sometiendo a la autoridad del Protectorado.

\section{INTERVENTOR DE CABILA Y JEFE DEL SERVICIO DE INFORMACIÓN DE LA Oficina Central de Melilla}

La lamentable actuación de la Policía Indígena durante el desastre de Annual provocaría su disolución en 1923. La decisión de otorgarle competencias militares (Real Orden Circular de 31-7-1914) había motivado que abandonara su principal misión, la acción policial, y este hecho comportó consecuencias nefastas para los intereses españoles. Asimismo, la torpeza de muchos de sus oficiales y la extralimitación en sus funciones serían elementos determinantes, aunque no los únicos, en el desastre y la consiguiente crisis en la zona ocupa$\mathrm{da}^{25}$. Un Real Decreto de 16-9-1922 sustrajo las funciones interventoras a los oficiales de la Policía en beneficio de interventores, militares en la inmensa mayoría de los casos, que dependían de unas nuevas inspecciones generales de Intervención Militar y Tropas Jalifianas y de Intervención Civil y Servicios Jalifianos, y la Real Orden Circular de 20-4-1923 dispuso la definitiva disolución de la Policía y el ingreso de sus componentes en las Mehal-las jalifianas ${ }^{26}$.

La disolución de la Policía motivó que algunos de sus oficiales pasaran a depender de la Inspección General de Intervención Militar y comenzaran a

24 Sobre las funciones de los jefes de las oficinas de la Policía Indígena y los interventores tras la ocupación de nuevas posiciones y la inmediata «pacificación» véase ViLLANOVA, José Luis, Los interventores..., págs. 92-103.

25 Sobre estas cuestiones véanse NIDO y TORRES, Manuel del, Misión política y táctica de las fuerzas indígenas en nuestra zona de penetración al Norte de Marruecos. Cooperación y articulación táctica de las tropas europeas con las antedichas en un Ejército colonial probable, Ceuta, Imprenta del Regimiento Serrallo, 1921; RAmos WhinthuYsSEn, Javier, Tropas Indígenas y Ejército Colonial, Sevilla, Lit. Tip. Gómez Hnos., 1921; RuIz AlbÉNIZ, Víctor, Estado actual del problema de España en Marruecos. Medios prácticos para resolverlo, Madrid, Sindicato de Publicidad, 1922; Expediente Picasso...; y Archivo General de la Administración -AGA, en adelante-, Caja M-20.

26 Sobre la Policía Indígena y la posterior organización de las Intervención véase VILLANOVA, José Luis, Los interventores..., págs. 28-60. 
ejercer su labor como interventores. El 1 de junio de 1923, Jiménez Ortoneda fue destinado a la Oficina Principal de Intervención de Batel, cuya jurisdicción abarcaba las cabilas de Beni Bu Yahi y Metalza, ambas fronterizas con la Zona francesa. En este puesto permanecería hasta el 22 de noviembre de 1924, cuando fue destinado a la Oficina Central de Intervenciones de Melilla. Durante este periodo, dio continuidad a los servicios políticos y de seguridad ${ }^{27}$, participó en operaciones de apoyo a las fuerzas militares en Beni Tuzin, Tensaman, Tafersit y Beni Ulichek, y ascendió a comandante por méritos de guerra (1-11-1924) ${ }^{28}$.

Ante la delicada situación por la que pasaban las tropas españolas a finales de 1924 e inicios de 1925, el Gobierno decidió proceder a la reorganización de las Intervenciones y de las Fuerzas auxiliares indígenas con objeto de establecer una mayor coordinación en la dirección de las operaciones militares ${ }^{29}$. Tras la reforma, el 1 de julio de 1925 Jiménez Ortoneda se hizo cargo de la sección política y del servicio de información de la Oficina Central de Melilla, que extendía su jurisdicción sobre las oficinas de las cabilas dominadas del $\mathrm{Rif}^{30}$, y en la que permanecería más de seis años (Figura $n^{\circ} 3$ ). La decisión de nombrarlo responsable de este servicio nos proporciona nuevas pistas acerca de sus conocimientos sobre el territorio y la capacidad de trato con los rifeños, pues pasaba a dirigir una sección y un servicio que constituían la columna vertebral de las Intervenciones. Los interventores tuvieron que desarrollar numerosas y complejas funciones $^{31}$, pero la principal consistía en el control político de las autoridades y de cualquier posible disidencia para asegurar la presencia española. Así lo manifestó la propia Delegación de Asuntos Indígenas al señalar que todas las actividades del interventor eran importantísimas «pero es más importante todavía, si cabe, la información [...] Un Oficial de Intervenciones [...] es ante todo un informador» ${ }^{32}$. Asimismo, el nuevo destino de Jiménez Ortoneda también era de una gran responsabilidad porque, a raíz de la celebración de la Conferencia hispano-francesa de Madrid (junio y julio de 1925)³, el Gobierno español planificó importantes acciones militares, para las que necesitaba contar con toda la información posible sobre el enemigo. Posteriormente, la ocupación de numerosas cabilas rifeñas obligaría a implantar el sistema de Intervención en ellas.

27 Entre los que pueden destacarse las gestiones para impedir que la cabila de Beni Said se sumase al enemigo en mayo de 1923; mes en el que ejerció provisionalmente el cargo de interventor de dicha cabila. AGMS, Leg. J-53.

28 AGMS, Leg. J-53 y «Expediente de la Pensión de Retiro de Jesús Jiménez Ortoneda».

29 Véase el Real Decreto de 20-5-1925.

30 Sobre la organización territorial de las Intervenciones véase VILLANOVA, José Luis, El Protectorado de España en Marruecos. Organización política y territorial, Barcelona, Bellaterra, 2004, págs. 261-266.

31 Véase Villanova, José Luis, Los interventores..., págs. 91-155.

32 Delegación De ASUntos Indígenas, Orientaciones a los Interventores en la labor de Protectorado en Marruecos, Tetuán, s. e., 1935, 2ª ed., pág. 72.

33 Sobre la Conferencia y sus resultados véase RAMIRO DE LA MATA, Javier, Origen y dinámica del colonialismo español en Marruecos, Ceuta, Ciudad Autónoma de Ceuta, 2001, págs. 274-291. 


\section{FIGURA N ${ }^{\mathrm{O}}$ 3: El COMANDANTE JESÚS JimÉNEZ ORTONEDA DURANTE SU DESTINO EN LA OFICINA CENTRAL DE INTERVENCIONES DE MELILLA}

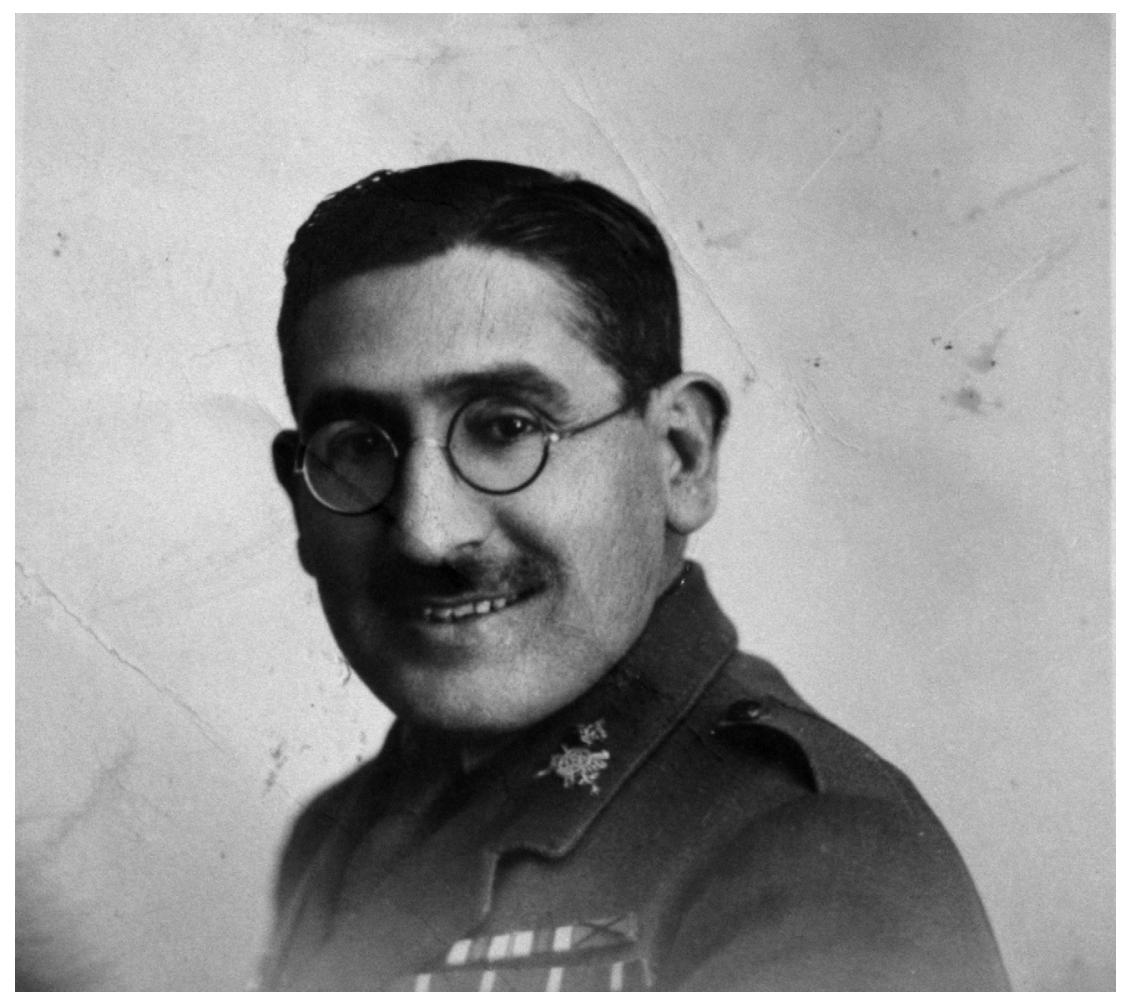

Archivo familiar de Jiménez Ortoneda.

En 1926, fue nombrado vocal del tribunal de los exámenes de árabe y chelja, una prueba de su competencia lingüística, y continuó demostrando su interés por incrementar sus conocimientos sobre la sociedad marroquí al cursar las asignaturas de Derecho Musulmán en la Escuela General y Técnica, obteniendo la calificación de Sobresaliente. Su destino en la Oficina Central no le impidió desplazarse constantemente a las cabilas donde realizó labores de información sobre las actividades del enemigo y organizó nuevas oficinas ${ }^{34}$. Su experiencia

34 AGMS, Leg. J-53. En uno de aquellos recorridos, efectuado en abril de 1929 para recaudar impuestos, fue acompañado por los botánicos Pío Font Quer y Carlos Pau Español y el geoquímico Rafael Candel Vila, quienes deseaban catalogar plantas de la zona. En la excursión localizaron tres nuevas Sideritis y Font Quer y Pau denominaron a una de ellas «Sideritis arborescens Salzm. var. Ortonedae», como muestra de agradecimiento por las facilidades que les había proporcionado Jiménez Ortoneda. Véanse FONT I QUER, Pío, «De flora occidentale adnotationes, VI», Cavallinesca, 3 (1-5) (1930), págs. 57-62 — cit. por GonZÁlez Bueno, Antonio y Gomis Blanco, Alberto, Los 
y buenos resultados obtenidos en el desempeño de la Intervención debieron ser determinantes para que fuera nombrado miembro de la Junta constituida en Tetuán para redactar el Manual para el Oficial del Servicio de Intervención en Marruecos en 1927. El Manual supuso un hito en la formación del personal de las Intervenciones Militares pues, por primera vez, se recogían de manera bastante detallada aquellos temas que debían dominar los interventores para llevar a cabo su compleja tarea ${ }^{35}$ y representó el mayor trabajo de recopilación y síntesis acerca de la labor interventora a lo largo de todo el Protectorado. Posteriormente se publicaron otras obras referidas al tema, pero ninguna abordó estas cuestiones con tanta amplitud. A pesar de las numerosas reformas organizativas y normativas posteriores, su contenido continuó vigente en gran parte hasta el final del Protectorado ${ }^{36}$.

\section{Agregado a la Comisión de Límites de Marruecos}

Uno de los aspectos destacados de la trayectoria profesional de Jiménez Ortoneda es su labor como agregado a la Comisión Internacional de Límites de Marruecos. La citada comisión se había creado en 1913, con la misión de efectuar el levantamiento topográfico de la fronteriza zona de los Protectorados de Francia y España y formar un documento cartográfico único y fiable, que sirviese de base al deslinde definitivo de las respectivas zonas de protectorado. Se trataba de una comisión mixta, de carácter técnico, que contaba con igual número de representantes nombrados por los gobiernos español y francés. La sección española dependía del Depósito de la Guerra en lo que afectaba al personal y aspectos técnicos de las operaciones, y del Alto Comisario de España en Marruecos para lo relativo al calendario de los trabajos, asistencia, protección y relaciones con los comisionados franceses y con las autoridades de la zona ${ }^{37}$.

La Comisión de Límites inició sus actividades cartográficas en abril de 1913, pero tras poco más de un año sus trabajos fueron suspendidos. El ejército francés, inmerso en el gigantesco esfuerzo de la Primera Guerra Mundial, decidió interrumpir las actividades que no fuesen esenciales; entre otras, las de de-

\footnotetext{
naturalistas españoles en el África Hispana, Madrid, Organismo Autónomo de Parques Nacionales, 2002, pág. 208- y CANDEl Vila, Rafael, «El Dr. Pío Font Quer y la investigación botánica en Marruecos», Collectanea Botanica, VII (I) (1968), págs. 166-206.

35 Véase INSPECCIÓN GENERAL DE INTERVENCIÓN y FueRZAS JALIFIANAS, Manual para el Oficial del Servicio de Intervención en Marruecos, Madrid, Talleres del Depósito de la Guerra, 1928.

36 En 1954 Tomás García Figueras, delegado de Asuntos Indígenas, destacó su utilidad. Véase García Figueras, Tomás, Cartas a los Interventores, mecanografiado, s. a. [1952-1956].

37 Estado Mayor Central. Servicio Geográfico del Ejército, Comisión del Estado Mayor en Marruecos. Comisión mixta de delimitación Hispano-Francesa en Marruecos. Comisión Geográfica de Marruecos. Breves extractos de la documentación existente en el Archivo (desde el año 1881 a 1936), Mecanografiado, 1947, CGEM (C-6bis-III, 10), págs. 73-74.
} 
limitación fronteriza. Por otra parte, las relaciones diplomáticas entre Francia y España se habían visto enrarecidas desde los inicios del conflicto bélico por la presencia en la Zona española de agentes alemanes implicados en la venta de armas a las cabilas opuestas al Protectorado francés ${ }^{38}$.

Condenada a la parálisis por las circunstancias de la guerra la Comisión de Límites pudo haber sido disuelta. Sin embargo, el Alto Comisario en Marruecos no estaba dispuesto a prescindir de una unidad cartográfica que tenía una excelente dotación de personal y de medios. La sección española de la Comisión de Límites era una de las mejores unidades con que contaba el Cuerpo de Estado Mayor para trabajos de campo, y su personal casi igualaba al que estaba destinado en la Comisión Geográfica de Marruecos, que tenía la responsabilidad de formar la cartografía de todo el Protectorado ${ }^{39}$. En consecuencia, el general Francisco Gómez Jordana, alto comisario en Marruecos, y el coronel Pío Suárez Inclán, jefe del Depósito de la Guerra, decidieron mantener en activo a la Comisión de Límites, y dedicar sus efectivos a realizar labores cartográficas complementarias a las desempeñadas por la Comisión Geográfica.

En esta situación permaneció la Comisión de Límites durante un lustro entero, hasta que el Alto Comisario y el Depósito de la Guerra decidieron reorganizarla y devolverla a su cometido original. La reorganización se hizo efectiva el 21 de febrero de 1920, en el marco de una reordenación general de los servicios cartográficos coloniales. La unidad quedó bajo el mando de un veterano cartógrafo del Estado Mayor, el teniente coronel José Molina Cádiz. Su plantilla estaba integrada por dos capitanes de Estado Mayor, dos maestros de taller, y seis obreros de la Brigada Obrera y Topográfica ${ }^{40}$. Para los servicios de escolta y portamira la comisión empleaba efectivos de las mías de Policía Indígena.

En 1921 Molina Cádiz tenía a sus órdenes a dos jóvenes capitanes, Sigifredo Sáinz Gutiérrez y Enrique Sánchez-Monge y Cruz, ambos bisoños en el trabajo cartográfico y con poca experiencia en suelo marroquíi ${ }^{41}$. Ninguno de los dos sabía árabe, ni chelja, y, como es natural, tenían escaso conocimiento del territorio y la sociedad local. Esta circunstancia explica que la Comisión de Límites buscase el refuerzo de un militar con probada competencia lingüística y un buen conocimiento del Rif oriental.

La agregación temporal a las unidades del Estado Mayor de veteranos procedentes de otras armas o cuerpos, fue una práctica común casi desde el inicio de los levantamientos cartográficos en Marruecos ${ }^{42}$. Y los motivos fueron casi siempre los mismos: las dificultades del trabajo de campo y de las labores de información en un entorno social y ambiental particularmente complejo, y la

38 Woolman, David S., Abd el-Krim...

39 Anuario Militar de España, 1915.

40 Véase la Real Orden de 21-2-1920.

41 AGMS, Leg. S-227, y AGMS, Leg. S-812.

42 Véase UrTeAgA, Luis, Vigilia colonial. Cartógrafos militares españoles en Marruecos, 1882-1912, Barcelona, Bellaterra \& Ministerio de Defensa, 2006. 
competencia lingüística. En los años que consideramos no existía ningún nomenclátor geográfico del Protectorado, ni tampoco un procedimiento tipificado para trasladar la fonética bereber al castellano. En la región oriental del Rif, zona elegida para los nuevos trabajos de la Comisión de Límites, se hablaban diversas variantes dialectales del chelja, además de árabe, y los accidentes topográficos recibían distintas denominaciones según las distintas cabilas. La fijación de topónimos constituía, en estas circunstancias, una tarea particularmente difícil y engorrosa. Por otra parte, los cartógrafos de la Comisión de Límites estaban forzados a mantener un contacto estrecho con los jefes de las cabilas y fracciones en las que se efectuaban los levantamientos. La demarcación fronteriza pactada en el convenio hispano-francés de 27-11-1912 había provocado el fraccionamiento del territorio de algunas grandes cabilas. Este era el caso de la cabila de Beni Bu Yahi, la elegida para efectuar los trabajos topográficos en 1921. Dicha cabila estaba compuesta por ocho fracciones, tres situadas en la Zona francesa, dos en la Zona española, y las tres restantes a caballo de la línea fronteriza ${ }^{43}$. Dado que los Beni Bu Yahi eran pastores trashumantes, la determinación precisa de sus zonas de aguada y espacios de pastoreo constituía una tarea esencial a la hora de efectuar un deslinde fronterizo que pudiese resultar aceptable para los poderes coloniales, y para la población autóctona.

La elección del capitán Jesús Jiménez Ortoneda para dar apoyo a la Comisión de Límites resulta poco sorprendente. Por entonces, como ya sabemos, llevaba casi quince años en Marruecos, hablaba árabe y chelja, y estaba al mando de la oficina de información de Afsó, en la cabila de Beni Bu Yahi. Jiménez Ortoneda se incorporó por primera vez como agregado a la Comisión de Límites en abril de 1921, en una coyuntura que pronto iba a dar un cambio muy brusco.

La primavera de 1921 fue una etapa de optimismo, casi de euforia, en la Comandancia de Melilla. Los movimientos de tropas ordenados por el general Manuel Fernández Silvestre habían extendido la zona ocupada desde el curso del río Kert hasta orillas del río Amekran, 50 kilómetros al oeste, y muy cerca ya de la cabila de Beni Urriaguel, considerada el núcleo de la resistencia rifeña. El proyecto de culminar la ocupación total del Protectorado parecía entonces al alcance de la mano. Sin embargo, como es sabido, el plan se torció por completo en muy pocos meses. Entre el 21 de julio y el 9 de agosto de 1921 el ejército español en Marruecos sufrió una dramática derrota, que supuso la pérdida de miles de vidas y llegó a poner en peligro a toda la Comandancia de Melilla ${ }^{44}$. El desastre de Annual tocó de lleno a la Comisión de Límites, que quedó desarbolada. El capitán Sánchez-Monge murió en la defensa de Monte Arruit, el 9 de agosto de 1921. Y su compañero, el capitán Sainz Gutiérrez, fue hecho prisio-

43 COMISIÓN INTERNACIONAL DE LÍMITES DE MARRUECOS, Notas relativas al trazado de la frontera. Sector de Beni Buyahi, mecanografiado, 1929, Archivo familiar de Jiménez Ortoneda.

44 Véase BALfOUR, Sebastián, Abrazo mortal... 
nero en el mismo lugar por las huestes de Abdelkrim. Jiménez Ortoneda, que tuvo la fortuna de sobrevivir a la insubordinación de las fuerzas de Policía Indígena que comandaba, pasó a las órdenes inmediatas del general Sanjurjo, nuevo jefe de la Comandancia de Melilla, como ya hemos comentado.

Tras el desastre de Annual, la labor de demarcación fronteriza quedó suspendida a causa de la inseguridad en la zona y el 4 de noviembre de 1921 el Alto Comisario ordenó el traslado de la Comisión de Límites a Ceuta, ya que no era posible seguir trabajando en la meseta del Guerruau. Jiménez Ortoneda, por su parte, permaneció en la cabila de Beni Bu Yahi y continuó al servicio de la Comisión de Límites hasta 1923, aunque resulta en extremo difícil reconstruir su actividad en este ámbito durante aquellos años. Es muy posible que su labor esencial fuese mantener el contacto con los oficiales que estaban al mando de las oficinas de Affaires Indigènes del Protectorado francés, e informar a sus superiores de los cambios que se estaban operando en la zona de frontera.

En efecto, el trazado fronterizo que se había acordado en 1912 se modificó de facto en numerosos puntos durante la guerra del Rif. En el curso del conflicto bélico las tropas francesas penetraron en la Zona española y establecieron posiciones defensivas al norte del río Uarga. Esta ocupación, que inicialmente debía tener carácter provisional, adquirió un carácter definitivo tras el acuerdo firmado entre los gobiernos de Francia y España el 25 de junio de 1925. El citado acuerdo dejó en Zona francesa las cabilas de Marnissa, Beni Bucelama, Fernassa, Beni Uanyel, Metiua, y parte de la cabila de Beni Zerual. En la campaña subsiguiente al desembarco de Alhucemas de agosto de 1925, surgieron nuevos puntos de litigio en las cabilas de Beni Bu Yahi, Gueznaya y Beni Zerual, en las que el ejército francés estableció y mantuvo posiciones avanzadas en áreas reclamadas por España. Para tratar de solventar estos problemas fronterizos se firmó un nuevo acuerdo el 10 de julio de 1926 que urgía la constitución, por segunda vez, de la comisión técnica de límites prevista en el convenio hispano-francés de 27-11-1912. En virtud de este acuerdo, el 26 de agosto de 1926 el Ministerio de la Guerra decidió reorganizar la Comisión de Límites para reanudar de inmediato los trabajos de demarcación ${ }^{45}$. La unidad fue considerablemente reforzada y se colocó bajo el mando del teniente coronel Antonio Aranda Mata, que desde 1923 tenía bajo su responsabilidad los trabajos geográficos en Marruecos. A las órdenes de Aranda Mata quedaron dos comandantes de Estado Mayor, un capitán del mismo cuerpo, un intérprete y, de nuevo, Jesús Jiménez Ortoneda, que por entonces había alcanzado el empleo de comandante.

El 17 de septiembre de 1926 Antonio Aranda Mata se desplazó a la cabila de Beni Bu Yahi, con el personal de la Comisión de Límites, para proceder a la selección y observación preliminar de los vértices de la triangulación de primer

45 Circular reforzando la Comisión de Límites de Marruecos, Diario oficial del Ministerio de la Guerra, Año XXXIX, nº 190, 26 de agosto de 1926, tomo III, pág. 626. 
orden que debía servir de apoyo al levantamiento fronterizo ${ }^{46}$. La sede de la unidad se trasladó a Melilla, para estar más próxima a la zona de operaciones, aunque Aranda Mata, que ostentaba el cargo de jefe de la Comisión Geográfica de Marruecos, permaneció en Tetuán. Para dirigir los trabajos de la sección de límites se nombró a un comandante de Estado Mayor, que quedó a cargo de los trabajos sobre el terreno: en 1926 y 1927 el comandante Emilio EstebanInfantes Martín y desde 1928 el comandante Darío Gazapo Valdés.

El levantamiento topográfico de la franja fronteriza se inició en el vado de Saf-Saf en el curso del Muluya, y prosiguió hacia el oeste hasta alcanzar la cima del Azrú Aksar, con un desarrollo de unos $200 \mathrm{~km}$ de longitud ${ }^{47}$. Los trabajos topográficos en el territorio de las cabilas de Beni Bu Yahi y Metalza estaban concluidos en enero de 1929. A partir de entonces restaba proceder al dibujo de la minuta a escala 1:20 000, que sería posteriormente reducida a escala 1:50 000. El trabajo final debía confrontarse con las minutas formadas a la misma escala por la sección francesa, a fin de trazar el documento definitivo. Sin embargo, esta confrontación no llegó a realizarse por razones de carácter político y no fue posible proceder al deslinde de la frontera. En consecuencia, los conflictos fronterizos en las cabilas citadas se mantuvieron, sin que la diplomacia encontrase un camino para resolverlos. Alejada la posibilidad de un acuerdo, la Comisión de Límites prosiguió sus levantamientos topográficos hacia el oeste, que en cualquier caso eran necesarios para la formación del Mapa topográfico del Protectorado español de Marruecos a escala 1:50 000 ${ }^{48}$.

Jiménez Ortoneda se había incorporado a las tareas de la Comisión de Límites el 5 de octubre de 1926. Su actividad tuvo varias facetas. En primer término realizó tareas de apoyo, esencialmente de tipo lingüístico, en los trabajos cartográficos; pero también se dedicó a sondear tanto las intenciones francesas como las de las elites locales. Al no poder acordarse los límites surgieron incidentes fronterizos, provocados por la política de hechos consumados que buscaron deliberadamente tanto los agentes franceses como los españoles. Los jefes de cabilas y fracciones, por su parte, trataron de sacar partido de esta rivalidad, desplazando los aduares a su conveniencia a un lado u otro de la frontera. Los conocimientos de Jiménez Ortoneda eran particularmente valiosos en aquellas circunstancias, de modo que se le mantuvo como informador de la Comisión de Límites hasta el 24 de febrero de $1932^{49}$.

En el archivo familiar de los descendientes de Jiménez Ortoneda se conserva la copia de tres informes del año 1929 relativos al trazado de la frontera en

\footnotetext{
46 Archivo General del Cuartel General del Ejército, Leg. A-287.

47 Montaner Canet, Federico, La Comisión Geográfica de Marruecos y Límites en la Feria de Muestras de Melilla, Melilla, Artes Gráficas Postal Exprés, 1930.

48 Sobre este mapa véase NADAL, Francesc, UrTEAGA, Luis y MURO, José Ignacio, «El Mapa topográfico del Protectorado de Marruecos en su contexto político e institucional (1923-1940)», Documents d'Anàlisi Geogràfica, 36 (2000), págs. 15-46.

49 AGMS, Leg. J-53.
} 
las cabilas de Beni Bu Yahi, Metalza y Gueznaya ${ }^{50}$. Los informes están mecanografiados y carecen de firma, pero la conjetura de que Jiménez Ortoneda pueda ser coautor de los mismos no parece demasiado arriesgada. En aquel momento formaban parte de la Comisión de Límites el comandante de Estado Mayor Darío Gazapo Valdés y el capitán Rafael Gómez Redondo, además de Jiménez Ortoneda. Gómez Redondo llevaba en Marruecos desde 1926, y Gazapo Valdés había llegado en 1927; ninguno de los dos sabía chelja ${ }^{51}$. Los informes muestran un conocimiento muy minucioso de la sociedad local, más propio del Servicio de Información de las Intervenciones que de una unidad cartográfica. En todos ellos se describe la composición de las cabilas, señalando las fracciones y subfracciones que las componen, llegando hasta el límite de las yemaas y poblados, e indicando, en cada caso, los líderes de cada uno de estos grupos. El objetivo obvio de los informes citados era señalar prioridades y facilitar diferentes alternativas ante eventuales negociaciones futuras en materia fronteriza.

Es seguro, por otra parte, que Jiménez Ortoneda se benefició intelectualmente de su dilatada relación con los cartógrafos del Estado Mayor destinados en Marruecos. El trabajo sobre el terreno, nunca interrumpido desde 1912, había permitido a los cartógrafos destinados en la Comisión Geográfica de Marruecos y Límites formarse una idea bastante clara de la estructura geográfica del Protectorado, y en particular de la atormentada orografía de la cadena del Rif. En 1930 el teniente coronel Rafael Alfonso de Villagómez y Núñez, que había trabajado en la Comisión de Límites desde 1914 a 1920, y que por entonces estaba al cargo de la Sección Geográfica del Depósito de la Guerra, publicó la que puede considerarse la primera interpretación moderna de la geografía del Rif's2.

Por entonces Jiménez Ortoneda era considerado como uno de los expertos en asuntos rifeños de la Alta Comisaría de España en Marruecos. Buena prueba de ello es el encargo que recibió en 1930 para dictar una conferencia sobre la región del Rif en el curso de perfeccionamiento de oficiales del Servicio de Intervención. Este es el origen del Estudio de la región del Rif, que se publicó en aquél mismo año ${ }^{53}$. El estudio de Jiménez Ortoneda tiene el mérito de ser una de las primeras monografías sobre el Rif debidas a un autor español; aunque se

50 COMISIÓN INTERNACIONAL DE LÍMITES DE MARRUeCOS, Notas relativas...; COMISIÓN INTERNACIONAL DE LÍMITES DE MARRUeCOS, Sector de Guezennaia, mecanografiado, 1929, Archivo familiar de Jiménez Ortoneda; COMISIÓN INTERNACIONAL DE LÍMITES DE MARRUECOS, Sector de Metalsa, mecanografiado, 1929, Archivo familiar de Jiménez Ortoneda.

51 AGMS, Legs. G-240 y G-2 131.

52 ALFONSO DE VillagÓMEZ Y NúÑEZ, Rafael, «Descripción geográfica de la zona de Protectorado español de Marruecos», Boletín de la Real Sociedad Geográfica, LXX (1930), págs. 97-102 con 8 fotografías.

53 Jiménez Ortoneda, Jesús, Estudio de la región del Rif, Conferencia del Comandante D.J.J.O., adjunto del Teniente Coronel Interventor. Región Melilla, Toledo, Imprenta del Colegio de María Cristina, 1930. 
apoyó ampliamente en el texto Le Maroc inconnu de Auguste Mouliéras ${ }^{54}$. Cabe señalar que en el mismo curso para los oficiales del Servicio de Intervención participó Emilio Blanco Izaga, con una conferencia sobre la vivienda rifeña ${ }^{55}$. La aparición casi simultánea de los estudios de Alfonso de Villagómez, Blanco Izaga y Jiménez Ortoneda quizá refleje algo más que una feliz coincidencia. Tras muchos años de moverse casi a ciegas, se estaban recogiendo los primeros frutos del esfuerzo africanista para conocer el territorio y la sociedad del Rif.

\section{Subdelegado de Asuntos Indígenas EN TetuÁN (1936)}

Las reformas militares impulsadas por Manuel Azaña, ministro de la Guerra del primer Gobierno provisional de la II República ${ }^{56}$, entre las que se encontraba la reorganización del Ejército de África, fueron acompañadas de diversas disposiciones oficiales para sentar las bases de una administración civil en el Protectorado y reorganizar las Intervenciones para desmilitarizarlas ${ }^{57}$. En este contexto, Jiménez Ortoneda fue destinado al Regimiento de Infantería ${ }^{\circ}$ 43 con sede en Ceuta en enero de 1932, abandonando su puesto en la Oficina Central de Melilla y, temporalmente, su vinculación con las Intervenciones. Posteriormente fue asignado a otras unidades de Infantería en Melilla, Alhucemas y Tetuán. Su larga trayectoria profesional en Melilla y el conocimiento de la ciudad debieron influir en su nombramiento como vocal efectivo de la Junta de la Plaza y juez permanente de Melilla. Asimismo, fue juez instructor eventual en Tetuán y quedó encargado del mando del destacamento de Alhucemas y de la Plaza de Tetuán en ausencia de los máximos responsables en diversas ocasiones. En agosto de 1934 se desplazó a Madrid para tomar parte en un curso de formación militar ${ }^{58}$. En esta ciudad, ascendió a teniente coronel el 19 de julio de 193559. Pero su estancia en la capital del Estado no se prolon-

54 Moga Romero, Vicente, «La celebración...». Véase Moulièras, Auguste, Le Maroc inconnu. Première partie. Exploration du Rif (Maroc septentrional), Paris, J. André, 1895.

55 BLANCo IZAGA, Emilio, La vivienda rifeña, Ceuta, Imprenta Imperio, 1930.

56 Véanse ALPERT, Michael, La reforma militar de Azaña, 1931-1933, Madrid, Siglo XXI, 1982; CARDONA, Gabriel, El poder militar en la España contemporánea hasta la guerra civil, Madrid, Siglo XXI, 1983; BusqueTs, Juli, El militar de carrera en España, Barcelona, Ariel, 1984; y, más concretamente sobre sus repercusiones en el Protectorado, MORALES LEZCANO, Víctor, "L'Exèrcit d'Àfrica i les reformes militars: 1931-1936», L'Avenç, 28 (1980), págs. 41-46.

57 Decretos de 3-6-1931, 16-6-1931 y 29-12-1931. Véanse Villanova, José Luis, «La pugna..., págs. 706-712 y Los interventores..., págs. 48-54.

58 Probablemente, el traslado se produjera a consecuencia de lo dispuesto por el Decreto de 20-10-1931 de aprobación de destinos en África, que limitaba «el tiempo de permanencia en Marruecos a cinco años, con obligado paso por la Península por lo menos durante un año». GIL Honduvilla, Joaquín, Marruecos i17 a las 17!, Sevilla, Guadalturia Ediciones, pág. 100.

59 Es posible que durante los años en los que estuvo destinado en Infantería escribiese el folleto Consejos al soldado en África, en el que daba muestra de sus amplios conocimientos de la realidad del 
gó demasiado: a finales del año fue nombrado interventor regional de $2 .^{\mathrm{a}} \mathrm{y}$ destinado a la Delegación de Asuntos Indígenas de Tetuán ${ }^{60}$.

El regreso a Tetuán y a las Intervenciones puede explicarse por el Decreto de 15-2-1935 que reorganizó los servicios de la Alta Comisaría, y especialmente la Delegación de Asuntos Indígenas que resultó ampliamente reforzada. Es probable que tanto su dilatada experiencia en la Oficina de Melilla como su propio interés ${ }^{61}$ influyeran en la asignación de su nuevo destino. Parece ser que, inicialmente, fue nombrado jefe de Policía ${ }^{62}$, pero sabemos con certeza que el 17 de julio de 1936 era subdelegado de Asuntos Indígenas y jefe de la Sección Política de la Delegación ${ }^{63}$. De ser correcto el primer dato, el ascenso a subdelegado pudo producirse después del triunfo del Frente Popular en las elecciones del 16 de febrero, tras las que el nuevo gobierno designó a personas que consideraba afines a su ideología para ocupar puestos de responsabilidad en el Protectorado ${ }^{64}$.

Los nuevos puestos que asumía Jiménez Ortoneda eran de una enorme trascendencia en aquellos momentos en que la mayor parte de los jefes y oficiales destinados en Marruecos conspiraban contra el régimen republicano. El Decreto de 15-2-1935 había encomendado al delegado de Asuntos Indígenas, bajo la directa dependencia del alto comisario, el ejercicio de la función política y tutelar de intervención, centralizando el control de las autoridades del país y los servicios de información, vigilancia y seguridad. Las mayores atribuciones que el decreto otorgaba a la Delegación obligaron al delegado a efectuar una reorganización interna el 3 de febrero de 1936. En base a esta reorganización, Jiménez Ortoneda tuvo a su cargo, como subdelegado, la inspección de entidades municipales, los asuntos económicos de los municipios rurales y de las yemaas y la supervisión de la población judía y de los tribunales rabínicos, y, como jefe de la Sección Política, los negociados de intervención, información, reclamaciones, bienes majzen, bienes habús y enseñanza marroquí. Evidentemente, sobre los negociados de intervención e información recaían las principales responsabilidades de la acción política. El primero tramitaba los asuntos referidos a justicia islámica, presos, emigración e inmigración, cuestiones reli-

Protectorado. Véase [Jiménez] ORTONEDA, [Jesús] Comandante, Consejos al soldado en África, s. 1. [Madrid], Imprenta del Depósito de la Guerra, s. a.

60 AGMS, Leg. J-53.

${ }_{61}$ Mercedes López Vienne, su nuera, y Mercedes Jiménez López, su nieta, en una entrevista mantenida el 1 de junio de 2008 en Madrid, comentaron que desde que estuvo destinado en Madrid, siempre quiso regresar a Marruecos.

62 Alcaraz CÁNOvas, Ignacio, «El Protectorado de España en Marruecos y el Frente Popular», Cuadernos Republicanos, 61 (2006), págs. 51-64.

63 AGMS, Leg. J-53.

64 Por ejemplo, Juan Moles Ormella ocupó el puesto de alto comisario que se encontraba vacante desde la dimisión de Manuel Rico Avello en diciembre de 1935 y el coronel Eleuterio Peña Delgado sustituyó en junio al teniente coronel Agustín Muñoz Grandes como delegado de Asuntos Indígenas. 
giosas, contrabando, relaciones con las autoridades de Ceuta y Melilla, desarme, licencias de armas, relaciones con el Majzen central, aspectos políticos de los impuestos majzenianos, pasaportes, la formación de los interventores y asuntos generales de política. Por su parte, el segundo se encargaba del cifrado, hojas diarias de información, confidencias e informaciones - incluyendo las de las zonas francesa e internacional de Tánger-, límites con las otras dos zonas, cartografía, control de prensa y de publicaciones, memorias de las cabilas y propaganda política en general ${ }^{65}$.

Los preparativos de la sublevación militar en el Protectorado fueron denunciados por José María Burgos Nicolás, interventor regional de Nador. En mayo se desplazó a Tetuán para ponerlos en conocimiento del alto comisario y del delegado de Asuntos Indígenas, pero éstos no manifestaron excesiva preocupación por la conspiración. Si que mostró más interés Jiménez Ortoneda, quien le pidió que siguiera recabando información para remitirla a Manuel Torres Campaña, diputado de Unión Republicana, con el propósito de que la trasmitiera a Diego Martínez Barrio ${ }^{66}$.

En la noche del 17 al 18 de julio de 1936, Jiménez Ortoneda se vio sorprendido en su oficina por las tropas sublevadas que ocuparon las dependencias de la Delegación a las órdenes del teniente coronel Juan Beigbeder. Tras evadirse, saltando por una de las ventanas, se dirigió a la sede de la Alta Comisaría para ponerse a las órdenes del coronel Peña, su inmediato superior. Ante la evidencia de que Peña estaba destituido, se dirigió a la Zona internacional de Tánger, pero fue detenido por los sublevados en el puesto fronterizo de Regaia y conducido a la fortaleza militar del Monte Hacho en Ceuta, donde ingresó en prisión el día $19^{67}$.

Las entrevistas mantenidas con familiares de Jiménez Ortoneda sugieren algunas pistas sobre su actitud ante la conspiración militar. Mercedes Jiménez López, su nieta, y Mercedes López Vienne, su nuera, nos informaron que, ante todo, se consideraba un militar profesional, respetuoso con la legalidad vigente y que no se había vinculado directamente con ningún partido político, aunque tenía un par de amigos republicanos en Tetuán ${ }^{68}$. Una estricta profesionalidad, el respeto al legalmente constituido régimen republicano, y la amistad que mantenía con algunos republicanos debieron influir decisivamente en que los conspiradores - a muchos de los cuales conocía personalmente por su larga estancia en Marruecos ${ }^{69}$ - no le considerasen una persona favorable a la insurrección.

65 AGA Caja M-2.456 y Villanova, José Luis, Los interventores...

66 AlCARAZ CÁnOvas, Ignacio, «El Protectorado...».

67 AGMS, Leg. J-53.

68 Probablemente se refirieran a Eliseo del Caz y a Antonio Ruiz, con quienes intentó huir a la Zona internacional de Tánger la noche del 17 al 18 de julio de 1936. AGMS, Leg. J-53.

69 Sus familiares nos informaron que, hasta 1936, consideró amigo personal a Beigbeder. En la declaración judicial efectuada el 13 de agosto de 1936, Jiménez Ortoneda explica que desde el cese de Beigbeder en las Intervenciones a consecuencia de la reestructuración realizada por Juan Moles, 
El triunfo de la conspiración militar en el Protectorado y la victoria franquista en la Guerra Civil supusieron el final de la carrera profesional de Jiménez Ortoneda. Tras pasar dos años detenido ${ }^{70}$, fue sometido a Consejo de Guerra el 30 de julio de 1938. El Tribunal lo condenó a la pena de dos años de prisión militar «como autor de un delito consumado de negligencia», y lo absolvió del «delito de desobediencia», del que también había sido acusado por el Ministerio Fiscal. Sin embargo, el auditor de las Fuerzas Militares de Marruecos discrepó de la sentencia por considerar que su actuación era constitutiva de un delito de «auxilio a la rebelión militar» y reclamó la revisión al Alto Tribunal de Justicia Militar con sede en Valladolid ${ }^{71}$. El 4 de octubre de 1938, el Alto Tribunal revocó la sentencia al considerar que Jiménez Ortoneda había realizado «actos positivos y de actividad ayudando a los insurgentes [sic]» al acudir a la Alta Comisaría e intentar ayudar a escapar a "dos significados dirigentes revolucionarios», el maestro Eliseo del Caz Rocha, presidente del Centro Obrero Republicano, y Antonio Ruiz, secretario de la Junta Municipal de Río Martín. Por estos hechos, le condenó «como autor de un delito consumado de auxilio a la rebelión militar» a la pena de «doce años y un día de prisión menor con las accesorias de inhabilitación absoluta durante la condena y pérdida de empleo». No obstante, trece días más tarde y a propuesta del Alto Tribunal, el general Franco, jefe del Estado, conmutó la sentencia por la de «tres años y un día de prisión menor y accesorias legales pertinentes» ${ }^{72}$.

En julio de 1939, una vez cumplida la pena de prisión y en situación de separado del servicio, Jiménez Ortoneda se desplazó a Madrid, donde fijó su residencia. El 29 de mayo de 1947 se le conmutó la pena de «tres años y un día de prisión menor» por la de «tres años con accesorias de suspensión de empleo»y causó baja definitiva en el Ejército, concediéndosele la pensión de retiro de te-

tras su segundo nombramiento como alto comisario en marzo de 1936, las relaciones entre ambos «se cortaron de raíz». Gil Honduvilla, Joaquín, Marruecos..., pág. 396. Por otra parte, su extensa colaboración con la Comisión de Límites permitió que trabajara estrechamente con Darío Gazapo Valdés, quien inició la sublevación en Melilla.

70 Sus familiares nos comentaron que no permaneció todo el tiempo en la prisión del Monte Hacho, sino que pasó a arresto domiciliario en Tetuán unos meses después de su detención.

71 Dos vocales del Tribunal también habían presentado sendos votos particulares por estar disconformes con el fallo dictado y considerar que los hechos constituían «un delito de auxilio a la rebelión militar».

72 AGMS, Leg. J-53. Desconocemos las razones de esta decisión pero, según sus familiares, pudieron influir en la reducción de la pena la declaración en su favor del mayor de sus hijos, Jesús Juan Jiménez Albéniz, teniente provisional que había resultado ciego absoluto a consecuencia de los combates en la Guerra Civil y, posiblemente, la Cruz Laureada que había recibido su hermano Juan. Por otra parte, tal vez convenga añadir que el propio Franco conocía a Jiménez Ortoneda. En el expediente del primer proceso instruido para su ascenso a comandante, el comandante Francisco Franco, que mandaba la vanguardia de la columna en el ataque a los Montes Uixan, elogió su comportamiento como ayudante y guía de dicha vanguardia. Véase «Expediente de la Pensión de Retiro de Jesús Jiménez Ortoneda». 
niente coronel unos meses más tarde ${ }^{73}$. Según los familiares entrevistados, Jesús Jiménez Ortoneda no manifestó resentimiento por su procesamiento y condena, pero sí, lógicamente, tristeza; una tristeza que se extendía también a su recuerdo de los sangrientos combates en Marruecos. No obstante, se mostraba muy reservado respecto a estos asuntos. Una vez establecido en Madrid se refugió en la familia, a la que dedicó el resto de su vida. Nunca más regresó a Marruecos, y apenas mantuvo contactos con sus antiguos compañeros del Protectorado. Falleció el 28 de octubre de 1976.

\section{CONCLUSIONES}

El estudio de la figura y la carrera profesional de Jesús Jiménez Ortoneda proporciona valiosas informaciones que permiten profundizar en el análisis de las Intervenciones del Protectorado español y matizar algunas de las conclusiones presentadas hasta el momento. Como interventor, demostró una profesionalidad que contrasta con la negativa imagen de dejadez, desinterés e incompetencia, que habitualmente se asigna a este colectivo profesional ${ }^{74}$. En las cabilas cuya administración le fue asignada, desempeñó simultáneamente los papeles de informador, traductor, juez, intendente y jefe militar. En tiempos de guerra el reto debió ser fenomenal. Y en cualquier época era una tarea delicada y compleja, en la que pesaba más el tacto que el reglamento, la experiencia y la intuición que la norma.

La trayectoria profesional de Jiménez Ortoneda es bastante típica en algunos sentidos. Como la mayoría de los interventores, fue un autodidacta en materia colonial y administrativa: el primer curso de formación para interventores no se organizó hasta 1928, y él mismo actuó como profesor en dicho curso ${ }^{75}$. Al igual que muchos de sus colegas, llegó muy joven a Marruecos, y sus primeros contactos y experiencias con la población nativa tuvieron lugar en el condicionado marco del mando de tropas coloniales. En ese aspecto su carrera puede compararse a la de Emilio Blanco Izaga que también fue destinado a Marruecos tras licenciarse en la Academia de Infantería en 1913 y que entre 1927 y 1945 estuvo asignado a las Intervenciones, alcanzando los cargos de subdelegado (1942-1944) y delegado de Asuntos Indígenas (1944-1945) ${ }^{76}$. Al igual que Blanco Izaga, Jiménez Ortoneda se interesó realmente por la sociedad y la cultura rifeñas. Aprendió árabe y chelja, y alcanzó un apreciable conocimiento del territorio del Rif. Su designación como experto agregado a la Comisión de

73 AGMS, Leg. J-53 y «Expediente de la Pensión de Retiro de Jesús Jiménez Ortoneda».

74 Blanco Moro, Agustín, Memorias del Sur. Recuerdos africanos de un salubrista, Melilla, Ciudad Autónoma de Melilla, 1997; Mateo Dieste, Josep Lluís, La «hermandad»...; ViLLAnOva, José Luis, Los interventores...

75 AGMS, Leg. J-53.

76 Blanco MORO, Agustín, «Otra lectura...» y HaRT, David M., «Introducción 1...». 
Límites de Marruecos es la mejor prueba de su competencia en este ámbito. Sin embargo, las semejanzas acaban aquí. Por una parte, Blanco Izaga no vivió en propia carne la guerra del Rif, pues estuvo destinado en la Península entre 1916 y 1927 y regresó a Marruecos cuando el conflicto había finalizado. Por otra, ejerció como interventor de cabila y como interventor regional durante más de catorce años —una vez que la Zona se encontraba «pacificada»—, por lo que su contacto cotidiano y directo con los rifeños fue mucho más prolongado y se desarrolló en un ambiente muy diferente ${ }^{77}$. Por último, al contrario que Jiménez Ortoneda, Blanco Izaga se sumó a la sublevación militar y desempeñó un papel destacado durante la Guerra Civil.

La dilatada experiencia de Jiménez Ortoneda en Marruecos fue valorada por las autoridades republicanas al conferirle el delicado cargo de Subdelegado de Asuntos Indígenas en 1936. Se trataba de un puesto de confianza, que implicaba un contacto estrecho tanto con el Delegado de Asuntos Indígenas como con el Alto Comisario de España en Marruecos. Esta circunstancia, unida a su probada profesionalidad, explica que no fuese contactado por los militares que prepararon el golpe de estado, a muchos de los cuales conocía personalmente. Su rectitud se puso de manifiesto, una vez más, el 17 de julio de 1936, pues fue uno de los pocos jefes militares que no se sumaron a la insurrección. No sabemos cuál hubiera sido su comportamiento si hubiese alcanzado la Zona internacional de Tánger, tal como pretendió hacer, pero sí sabemos que demostró lealtad al régimen republicano, y que pagó por ello con la cárcel y con la liquidación de su carrera profesional.

Recibido: 12-11-2008

Aceptado: 24-03-2009

77 Jiménez Ortoneda, aunque estuvo destinado doce años en la Policía Indígena, ocupó el cargo de interventor de cabila durante menos de dos años (1923-1924) y en plena guerra del Rif. Posteriormente pasó a la Oficina Central de Melilla y a la Delegación de Asuntos Indígenas, donde el contacto directo con las cabilas era mucho menor. 